\title{
O engajamento político dos jovens no movimento hip-hop*
}

\author{
Rosangela Carrilo Moreno \\ Ana Maria F. Almeida \\ Universidade Estadual de Campinas, Faculdade de Educação
}

\section{Introdução}

O que leva alguns jovens a se envolver com a militância política, criando ou participando de grupos empenhados em ações coletivas?

Trata-se de uma questão recorrente nas discussões e debates sobre a participação política que tiveram lugar nas ciências sociais ao longo da segunda metade do século XX e que diz respeito à maneira como se pode explicar o engajamento individual na ação coletiva, isto é, vinculada a grupos que defendem determinados interesses.

Esses debates vêm na contracorrente de uma crença generalizada em certos meios, de que a ação coletiva pode ser o resultado natural e mesmo automático de transformações sociais que, ao produzir separações e oposições, daria origem a grupos dotados da capacidade de lutar por seus interesses. Assim, tudo se passaria nessa lógica, como se, por exemplo, a formação da

* As autoras agradecem o apoio da Coordenação de Aperfeiçoamento de Pessoal de Nível Superior (CAPES) e da Fundação de Amparo à Pesquisa do Estado de São Paulo (FAPESP). classe trabalhadora pudesse produzir, por si mesma, o movimento dos trabalhadores (Offerlé, 1994).

Confrontando essa crença, algumas hipóteses foram levantadas. No pensamento político moderno aceitou-se, durante muito tempo, como mostra Ostrom (2000), a ideia de que os grupos tendem a se formar e a se engajar em ações coletivas sempre que seus membros se beneficiem conjuntamente dessa ação. Com a publicação, em 1965, do livro A lógica da ação coletiva, de Mancur Olson, essa concepção foi desafiada pela hipótese, apresentada logo no início do livro, de que indivíduos racionais não tendem a agir para atingir interesses comuns ou interesses do grupo, a não ser quando recebem sanções ou recompensas para tal. Embora escrito em meio à agitação dos anos sessenta, o autor entendia, na melhor tradição da teoria da escolha racional, que a ação coletiva acontecia, principalmente no caso dos grandes grupos, como a soma de decisões estratégicas de indivíduos particulares, induzidos a participar de um esforço de grupo por meio de incentivos e sanções (Edelman, 2001).

Muito do que se escreveu sobre engajamento a partir daí teve como objetivo discutir essa hipótese. 
Uma das críticas dirigidas a Olson incide na maneira como se constrói seu individualismo metodológico, que toma o indivíduo desvinculado de todo constrangimento social, "livre para agir e autor de todos os possíveis” (Offerlé, 1994, p. 53).

Ao longo do tempo, especialistas que se debruçaram sobre a questão pretenderam explicar o engajamento como um resultado da "mobilização de recursos", dos "processos políticos" e dos "novos movimentos sociais” (Edelman, 2001). Apesar de toda essa movimentação, o discurso especializado chegou aos anos 2000 lamentando a segmentação dos pesquisadores. Ela seria responsável, para alguns, pelo pouco acúmulo da área e por suas muitas perguntas ainda não respondidas (Edelman, 2001, Fillieule, 2001). Entre essas questões, encontra-se justamente o problema da entrada em militância que pretendemos abordar neste artigo.

Outro interesse da questão apresentada encontrase em discuti-la focalizando os “jovens”. Em nosso vocabulário, essa categorização não interage de forma rígida com uma idade específica. Pretende apenas dar conta de indivíduos que compartilham certa posição no espaço social caracterizada essencialmente por uma idade entre 13 e 22 anos e a ausência de dependentes como filhos ou esposos. ${ }^{1}$

Por fim, importa notar que perguntar sobre as condições que tornam possível o envolvimento de jovens com a ação política significa principalmente enfrentar as dificuldades de definir determinadas ações como "políticas", o que pede maior qualificação da ideia, bastante frequente na literatura sobre jovens no Brasil, de que a militância política desse grupo está em declínio ou desapareceu (Abramo, 1994a).

Essas questões são discutidas neste artigo a partir de pesquisa que focalizou um grupo de jovens rappers que se identificam como negros. O grupo foi

${ }^{1}$ Para o leitor interessado numa discussão mais precisa da categoria idade, indicamos o muito conhecido artigo de Pierre Bourdieu (1983) e o artigo de Abramo (1994b) que identifica as transformações históricas que permitiram ou forçaram o adiamento da entrada na vida adulta e o resultante aparecimento dessa fase da vida que denominamos juventude. muito atuante na origem do "movimento hip-hop" de Campinas, em meados dos anos de 1990, e suas ações foram fundamentais para dar concretude à ideia de que havia um movimento hip-hop na cidade, qual era ele, que propostas tinha, que iniciativas defendia. Essas ações foram empreendidas em meio a alianças e disputas com outros jovens também envolvidos com o hip-hop e/ou com outros movimentos, como o movimento negro ou de estudantes secundaristas. Em 2001, ao final de um longo processo, seus membros conseguiram o apoio da prefeitura municipal da cidade, assumida pelo Partido dos Trabalhadores (PT) naquele ano, para a criação da Casa do Hip-Hop de Campinas. ${ }^{2}$ Essa Casa funcionou como um espaço de discussão e desenvolvimento de atividades do hip-hop, aglutinando artistas e estabelecendo uma proposta de formação nas artes do hip-hop entre 2002 e 2004, quando foi desativada após a posse do prefeito eleito. ${ }^{3}$

Este artigo centra-se na primeira etapa desse processo, quando os jovens em foco engajam-se no rap, terminando por criar uma associação que congregava praticantes do hip-hop para além da cena rapper, incluindo grafiteiros e dançarinos de break, além de um grupo de moças que, embora não praticantes das modalidades de hip-hop citadas, davam importante suporte intelectual e logístico ao grupo. Por volta do ano 2000, inspirado pelas discussões em andamento na cena hip-hop norte-americana, o grupo passa a

\footnotetext{
${ }^{2}$ Para a reconstituição da história desse grupo, assim como
} dos percursos sociais dos indivíduos particulares, a pesquisa apoiou-se em dados produzidos por meio de um estudo de sua produção artística, de entrevistas minuciosas, realizadas em uma ou duas rodadas, de observações dos seus encontros, das suas atividades ligadas ao hip-hop e do contato com os políticos profissionais da cidade, todas registradas em caderno de campo. Além disso, foram realizadas entrevistas com políticos profissionais ligados ao grupo, bem como o estudo de matérias de jornais, textos de legislação, folhetos e documentos diversos produzidos pelo grupo. Ver Moreno (2007) para mais detalhes.

${ }^{3}$ Ainda a respeito da Casa do Hip-Hop, cabe sublinhar que o novo prefeito autorizou sua reabertura em 2006, embora com diminuição importante no escopo de suas atividades. 
identificar o trabalho desenvolvido por essas moças como o $5^{\circ}$ elemento do hip-hop, o "conhecimento". Esse grupo seria, nesse discurso, aquele que guardaria o "conhecimento" do hip-hop. ${ }^{4}$

A associação recebeu o nome de Posse Rima \& $\mathrm{Cia}^{5}$ e seus membros, principalmente o grupo que esteve na origem da sua constituição, são aqueles que vão se empenhar na luta pela criação da Casa do HipHop de Campinas. Nosso objetivo aqui é explorar uma visada analítica que permita compreender o envolvimento do grupo numa atividade artística de protesto e seu desdobramento numa militância estruturada em formato mais próximo daquele das organizações sindicais e partidárias.

Para isso, trabalhamos com dois eixos analíticos principais. Por um lado, inspiradas pelos trabalhos de Bourdieu (2000) e, principalmente pela operacionalização de suas hipóteses na discussão sobre a militância política proposta por Johanna Siméant (2001), procuramos explicar a presença, nesses jovens, de uma disposição para a militância política. Nesse caso, propusemos uma análise das condições objetivas e subjetivas em que se deu sua socialização, centrada especialmente numa interrogação sobre as características das configurações sociais, no sentido dado a essa expressão por Norbert Elias (1980), em que estiveram inseridos, focalizando principalmente as redes familiares e de sociabilidade que puderam construir e por onde puderam transitar. Construímos, assim, as trajetórias sociais de suas famílias, procurando captar as permanências e as transformações com que se confrontaram ao longo de suas histórias.

\footnotetext{
${ }^{4}$ No estado atual de formulação da questão, os outros quatro elementos do hip-hop são: o DJ (disk-jockey), o MC (mestre de cerimônias), o break e o grafite.

${ }^{5}$ Nas palavras de uma participante desse universo que veio a desenvolver uma dissertação de mestrado sobre mulheres no hip-hop, "Posse é uma organização de formação autônoma que concentra, no caso de Campinas, um número variado de grupos de rap que buscam ações coletivas mais estruturadas dentro de seu território” (Lima, 2005, p. 6).
}

Por outro lado, inspiradas pelos trabalhos de Olivier Fillieule, procuramos compreender como essas disposições puderam se traduzir numa ação efetiva, no caso a aproximação com o hip-hop e, posteriormente, a luta pela criação da Posse. Trabalhamos, nesse eixo, com a ideia de processo, pensando o militantismo como "uma atividade social e dinâmica" (Fillieule, 2001, p. 200), o que significa, em termos claros, "integrar uma dimensão temporal à análise" (idem, ibidem) também com respeito a essa questão da "passagem ao ato". Nessa perspectiva, a entrada em militância não é vista como um desdobramento automático resultado de disposições individuais construídas ao longo do processo de socialização focalizado anteriormente, mas como o resultado, nunca definitivo, dos encontros, das interações, da participação em redes de relações de vários tipos inclusive afetivas - que se desenvolvem num espaço social historicamente definido, isto é, concretizado em instituições, modos de fazer, modos de pensar que orientam microdecisões cotidianas que, por sua vez, configuram, num determinado momento do tempo, a ação política coletivamente articulada.

Em termos do arrazoado desenvolvido antes, o processo em questão só pode ser compreendido a partir de uma análise que explore, ao mesmo tempo, a presença de disposições para a militância e sua conformação ao longo do tempo, resultado do processo de socialização, assim como as condições objetivas que, definindo o espaço de possibilidades das interações, permitiram a ativação dessas disposições, produzindo ações efetivas num espaço social específico. Assim, a visada analítica explorada aqui procura demonstrar que, sem que esteja presente um conjunto de disposições, a tendência para a ação coletiva será mais tênue, ao mesmo tempo em que considera que tais disposições não são suficientes para explicar por si mesmas a entrada em militância. Para explicar isso, exige-se também uma análise das características do espaço social concreto em que se moveram os indivíduos em foco, o que significa tratar o caso historicamente, reconstituindo, na medida do possível, a configuração social específica por onde transitavam esses jovens no 
momento da iniciação na produção de rap e, posteriormente, na criação da Posse.

Esse raciocínio organiza, então, a estrutura do texto. Ao final, esperamos que esta análise, construída a partir de um grupo específico cuja história pôde ser bem delimitada no tempo e no espaço, possa contribuir para compreender com maior precisão o processo de construção e as mutações da experiência militante, assim como para captar as complexidades dos processos de socialização e de seus efeitos.

\section{Rap como militância}

O rap é uma das formas expressivas do hip-hop, ${ }^{6}$ cujas origens remontam a meados da década de 1970, associadas aos "deslocamentos sociais e mudanças estruturais, definidores do clima urbano do sul do Bronx uma das mais pobres comunidades de Nova York e da nação” (Martinez, 1997, p. 272, tradução livre) -, que enfrentava, na época, um forte "isolamento social, fragilidade econômica, meios de comunicação truncados e um encolhimento das organizações de serviço” (Rose, 1994, p. 33-34, tradução livre). Embora vinculado às tradições culturais negras, o rap também foi influenciado pela música caribenha de origem africana (Rose, 1994; Silva, 1998) e consiste numa forma musical na qual um texto é recitado enquanto é acompanhado por uma batida rítmica de baixo ou percussão. ${ }^{7}$

Dentro do rap existem duas atividades distintas: uma primeira, executada pelo MC (mestre de cerimônia), consiste em recitar um texto de forma rápida e incisiva. A segunda, executada pelo DJ (disk-jockey), consiste em manusear o equipamento de som, produzindo a base musical para os rappers cantarem e os dançarinos de break dançarem. Esse formato, que separa em duas pessoas essas atividades, fixou-se a

${ }^{6}$ As outras são o break (dança), o grafite (expressão plástica, pintura, em forma de desenhos e letras), a que se acrescentou, mais recentemente, o conhecimento (que significa conhecer a própria realidade de exploração a que são submetidos os negros).

${ }^{7}$ Para uma apresentação e discussão das premissas musicais do rap, ver Smith (2000). partir do final dos anos de 1980. O MC e o DJ são, assim, dois artistas que dividem o mesmo palco.

A política pode ser encontrada em duas dimensões do rap. Por um lado, a participação do DJ vai além da simples produção de um arquivo musical, da organização da ordem de saída das músicas e seu encadeamento, na medida em que ele se apropria de sons produzidos por outros (música ou textos) e os expõe como algo novo por meio de uma técnica denominada sampling, que consiste em misturar duas ou mais canções, trechos de discursos a canções, sem se dispor a pagar pelos direitos autorais das obras utilizadas. ${ }^{8}$ Por outro lado, o MC apresenta textos que, em certos casos, têm forte conteúdo político, tornando possível definir o rap, como o faz Martinez (1997, p. 272), como um tipo de "música com mensagem".

Como mostram alguns analistas, o rap com mensagem propriamente "política” se consolidou em meados dos anos de 1980, com grupos da costa oeste dos Estados Unidos, como Boogie Down Productions e Public Enemy. Este último é considerado o mais representativo do gênero, concentrando em suas letras relatos e denúncias das injustiças sofridas pela comunidade negra nos Estados Unidos. O líder do grupo, Chuck D., tem uma história peculiar. Recebeu educação superior (college) e era filho de ativistas de movimentos dos anos de 1960. Além disso, havia participado de um programa de treinamento denominado Afro-american experience (Experiência afro-americana), dos Black Panthers. Após seu surgimento na cena artística, uma série de grupos o seguiu, estabelecendo essa versão do rap no centro da cena hip-hop norte-americana. ${ }^{9}$

No Brasil, o desenvolvimento da versão política do rap foi bastante precoce e continua visível. Um

${ }^{8} \mathrm{O}$ que os faz ser percebidos como subversivos (Austin, 1992, apud Martinez, 1997). Essa, no entanto, é uma prática que o sucesso comercial do rap tem inibido, na medida em que as grandes gravadoras, ao assinar com um artista, tendem a inibir o sampling ou a pagar pelos direitos autorais (idem).

${ }^{9}$ Para aprofundar essa discussão, ver Martinez (1997). Ver também Lima (2005), para uma excelente descrição da cena campineira no período em foco. 
dos grupos mais representativos dessa vertente, o Racionais MC's, fez sua primeira gravação na coletânea Consciência Black, em 1988; seu primeiro disco solo, Holocausto Urbano, foi lançado em 1989 com uma turnê nacional. Em 1991, o grupo abriu os shows da turnê brasileira do Public Enemy.

Embora seja patente o caráter contraditório da produção dos grupos de rap, cujas letras podem expressar posições sexistas e às vezes apenas ingenuamente românticas, revelando diferentes modos de pensar que orientam a visão sobre o rap (Weller, 2002), ${ }^{10}$ não há dúvida de que, para se candidatarem e permanecerem na cena rapper, os músicos têm que ativar um repertório suficientemente fornido de mensagens políticas de contestação do status quo e de denúncia social, na maioria das vezes bastante elaboradas.

É nesse sentido que a aproximação com o rap pode ser compreendida como a aproximação com uma atividade de militância política, como reivindicado pelos membros do grupo em foco:

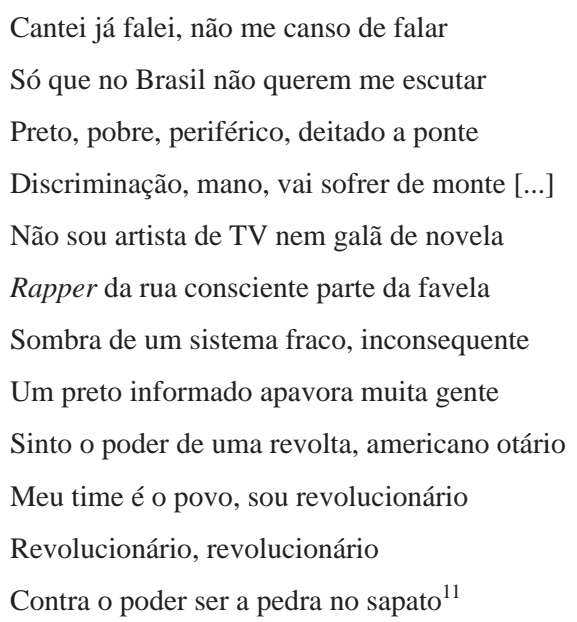

${ }^{10}$ Weller (2002, p. 7), em estudo comparativo entre rappers paulistas e de origem turca que vivem em Berlim, constatou duas orientações nas práticas associativas dos jovens: uma, geracional; outra, denominada pela autora de classista, vê o rap articulado a aspirações sociopolíticas. Essas diferenças de orientação teriam efeito sobre a maneira como as letras das músicas e outras dimensões da produção artística são encaradas e vividas.

${ }^{11}$ Trecho da música Revolucionário, do grupo Conceito Real, de Campinas.
Quais são, portanto, os elementos que contribuem para explicar a disposição dos jovens em foco, de se aproximar da música de protesto e denúncia social e sua pulsão para o protagonismo político que parece tê-los guiado na direção do militantismo no movimento pela criação da Casa do Hip-Hop de Campinas? Essa é a pergunta que procuramos responder no próximo item.

\section{Disposições para o protesto e a denúncia social}

Nesta pesquisa, procuramos responder a essa pergunta explorando as histórias de socialização dos jovens em questão.

Consideramos, para isso, suas propriedades sociais e as de suas famílias, buscando captar, por meio de entrevistas aprofundadas e, em certos casos, repetidas, o percurso social do grupo familiar, os valores reforçados na educação das crianças relativos a diferentes esferas de ação social, seja por meio da análise dos discursos explícitos, seja pelas orientações expressas na forma de organização dos modos de vida que definem o pertencimento a um grupo social específico. Interrogamos, assim, sobre as perspectivas construídas na relação entre os jovens e os membros das gerações mais velhas presentes em suas famílias ao longo de sua educação, pesquisando a relação que estabeleceram com a escola, com o trabalho, com a remuneração, entre outros.

Recuperando a trajetória do grupo de jovens que se empenhou na construção da Casa do Hip-Hop de Campinas, vimos que, oriundos de grupos sociais menos privilegiados economicamente, eles dispunham de um conjunto de condições particulares que foram decisivas para que pudessem realizar esse tipo de investimento.

\section{Proximidade com um circuito black}

Ivo, um rapper que participou ativamente do processo, desde a organização da associação de rap até à criação da Casa do Hip-Hop, afirma que o rap está "no sangue”. Essa percepção está associada diretamente ao contato que ele teve, desde a infância, com a música, 
pois o avô que morava na mesma casa, frequentava assiduamente os "bailes”, assim como sua mãe, que tinha como preferência musical o samba-rock, um estilo também associado ao circuito black, entendido aqui como um espaço de atividades de diferentes tipos que, de maneira mais e menos explícita, vincula-se aos movimentos dos negros norte-americanos, mesmo que às vezes retraduzido no repertório nacional. Para o caso dos jovens em questão, a atividade central é a música. Assim, em vários casos, James Brown aparece ao lado do samba de raiz.

Ivo tinha cerca de 12 anos de idade quando conheceu e passou a conviver com o pai que, ele descobriu, “dava som” em bailes, mantendo em casa um grande acervo musical composto por artistas como Tim Maia, Jorge Ben Jor e James Brown, entre outros.

Essa experiência apresentada de forma particular está presente na trajetória de todos os jovens em foco. É comum a presença da música em festas de família, como no caso de Cynthia, que lembra da família reunida ao som de samba de raiz; de Vânia, que presenciou o pai tocando vários instrumentos, como flauta e violão; e de Túlio, que viu muitas vezes sua mãe tocando sanfona. Embora os pais estejam, para a maioria, ausentes, a rede familiar é bastante extensa e o avô materno parece ter sido com certa frequência um personagem central na história da aproximação dos jovens com a música negra. As mães, por sua vez, tocavam instrumentos ou cantavam em festas de família, de vizinhos etc., e iam a bailes onde se tocava black music. Além disto, eram as estações de rádio que tocavam esse tipo de música, as mais sintonizadas em casa.

Da análise da cronologia das experiências que os jovens consideram significativas para explicar sua adesão ao rap emerge, assim, a ideia de que sua identificação com práticas culturais entendidas como típicas dos grupos negros antecede e, em alguma medida, prepara sua identificação com o rap, a que chegam por outras vias que não a família. ${ }^{12}$

${ }^{12} \mathrm{O}$ gosto por esse estilo musical, assim como determinados modos de se portar, adquiridos em um processo de socialização,
Participando, desde a adolescência, de uma rede de sociabilidade tecida em torno da comunhão de gostos musicais, ali entraram em contato com o rap. Fabiano, por exemplo, descobriu o rap a partir dos bailes que aconteciam na escola onde estudava e onde fez alguns amigos. Maiara conheceu uma amiga que participava do movimento negro e que lhe apresentou o rap, enquanto Francisco escutou o primeiro rap em uma fita cassete emprestada por um amigo da escola. Os grupos de rap que eles conheceram e de que se tornaram fãs nesse período foram Racionais MC’s, Thaíde e DJ Hum.

Mano Brown, compositor do grupo Racionais, fez em 1994 uma música chamada Racistas e Otários, cuja letra dizia:

Os poderosos são covardes, desleais
Espancam negros nas ruas por motivos banais [...]
Será que eles veem em nós um marginal padrão
50 anos agora se completam
Da lei anti-racismo na constituição
Infalível na teoria
Inútil no dia-a-dia
Então que fodam-se eles com sua demagogia
No meu país o preconceito é eficaz
Te cumprimentam na frente
E te dão um tiro por trás

Essas canções de rap provocam identificação pessoal nos jovens, como mostra Ivo:

\footnotetext{
Foi uma coisa de identificação. Um dia eu estava na minha casa com os meus primos. [...] E ali, assim, tinha meus amigos daquela época de molecada, eu andava na rua, e o cara: "Pô, escuta essa música aqui, que o cara trouxe de não sei onde”. A gente escutava e falava: "Nossa, cara, o que ele falou nessa música? Parece comigo. É o que eu vivo e tal”. E foi essa identificação que foi um ímã para mim. (Entrevista de pesquisa, Campinas, 2006)
}

permite que esses jovens possam se identificar em outros espaços que não os do universo familiar. Para compreender isso, é preciso mobilizar o gosto e o estilo de vida como unidade de análise (Bourdieu, 1994). 
A identificação com a canção do grupo Racionais não é apenas metafórica. Em suas vidas cotidianas, os jovens estavam continuamente confrontados a experiências de racismo e privação material.

\section{A experiência do racismo e da privação}

Fabiano, aos sete anos, como não teve aceita sua matrícula na escola pública mais perto de sua casa (por não ter cursado a educação infantil), não teve outra alternativa a não ser cursar a primeira série em uma escola mais afastada, localizada num bairro de características sociais bastante distintas do seu. Lá, ele se viu na necessidade de conviver com crianças que considerava “diferentes”. Isso, segundo ele, deu origem a um sentimento de exclusão.

Então, na escola eu não me sentia assim totalmente integrado. Tive muitos amigos ali que tinham grana, que moravam em grandes casas ali no Primavera [nome do bairro], em casas em que você se perdia dentro, e que fizeram amizade porque gostavam de mim pelo que eu era. Inclusive eu levava eles lá na minha casa no Santa Cândida, na casa sem reboco, pequenininha e tal. Levava eles para lá e tinha amizade normal. Mas também fui discriminado um pouco na escola, eu senti que não conseguia me integrar completamente. E eu cresci até com certo complexo. Então eu não gostava do meu cabelo, não tinha muita auto-estima. (Entrevista de pesquisa com Fabiano, Campinas, 2006)

Frequentemente esses jovens viviam situações de violência tanto física quanto simbólica quando a questão da cor da pele estava em jogo.

Os caras [se refere aos policiais] já me pararam e falaram: "Porra neguinho, você é trabalhador, o que é que você está fazendo com essa calça larga, pô, olha essa cara de estudante. o que que é isso?” [...] "Puta, mano, você tem maior cara de trabalhador, ô louco”. Eu vou ter que falar o que para o cara? Quem vê cara não vê coração. Sou trabalhador, mas não vou deixar de ser rapper. Porque eu trabalho, eu não vou deixar de ser rapper. Porque eu estudo, eu não vou deixar de ser rapper. É cômico depois, mas na hora você sente raiva.
Depois você dá risada, se torna uma história boba, mas marca você. [...] E o que chama a atenção deles é a roupa, o estilo, é porque a gente é assim, bando de negrão. Você está tachado, bando de negrão de calça larga, porra. Um bando de negrão de calça larga, andando à noite na rua, não pára que é bandido, mano, é muito. Se preto anda de calça larga na rua e um monte de gente junto, é bandido, está roubando, é tumulto, mano. [...] É assim que eles veem a gente, meu, não vai parar. Outro dia eu estava vindo do trampo para a minha goma ${ }^{13}$ e eu estava na moto, de repente uma viatura viu eu vindo. Estava de mochila, vindo do trampo, horário de serviço, a viatura começou a me seguir. Eu fiquei naquela, se eu parar? Pô, eu estava andando numas ruas no meu bairro lá que não tinha ninguém e, pô, dá medo você parar numa rua que não vai ter ninguém, não vai ter testemunha. Aí eu falei: “Ah, não, mano, não vou parar não, vou lá para a minha goma. E aí eu comecei a acelerar a moto, acelerar a moto, e os caras começaram a vir atrás de mim [...]. De repente, o cara acionou a sirene, aí eu cortei uns caminhos, parei na porta da minha casa, desci da moto e falei: "Mano, sou trabalhador”. Aí o cara já: “Mano, mas você não devia ter acelerado”. Eu falei: “Não, não, sou trabalhador, mano, eu não vou parar em qualquer lugar, mano”. Aí na porta da minha goma os caras já: “Porque você parou aqui?” “Aqui é minha casa, se você quiser pode entrar e ver que é minha casa". Aí o cara ficou meio naquela e tal, fez umas perguntas, pediu documento, mas ficou mais a pampa". (Entrevista de pesquisa com Ivo, Campinas, 2005)

O rap, assim, indica para esses jovens uma outra forma de entender o mundo que os cerca. Ao mesmo tempo, lhes dá instrumentos para operacionalizar essa mudança de olhar. É Fabiano que conta ter vivido um início de revolta na adolescência. E foi nessa época que ele conheceu o rap. "Comecei a ouvir Racionais e aí foi um achado para mim. Eu comecei a entender o mundo que eu vivia”.

O fato de o rap lhes oferecer uma chave para entendimento do mundo no momento crucial em que se esboça sua autonomização em relação a suas famí-

\footnotetext{
${ }^{13}$ Goma é o termo usado para se referir à casa.
} 
lias marca profundamente suas biografias, levando-os a pensá-lo também como espaço possível de ação, sobretudo artística ou profissional, pelo menos num primeiro momento.

No entanto, embora o contato com o circuito black e a experiência do racismo sejam elementos importantes para explicar o sentimento de identificação que os jovens dizem ter sido despertado pelo rap, e, dentre suas várias formas, aquele do grupo Racionais, é na análise das histórias de suas famílias que se explicitam os processos que permitiram a construção de disposições necessárias para o protagonismo político inerente à militância.

\section{Uma mobilidade social relativa e sua moral correspondente}

Como aponta Bourdieu (1979), o afrouxamento de uma situação de miséria é condição necessária para que se possa anunciar mais uma “força revolucionária” que vá além dos sentimentos de revolta, expressa de modo incerto e incoerente. No caso dos jovens em foco, essa hipótese se sustenta com bastante força.

Nesse caso, a mutação de uma revolta em arte, anunciada em espaços de sociabilidade e lazer de maneira organizada, coletiva e, posteriormente, desenvolvida no espaço da política profissional, foi empreendida por jovens que cresceram numa posição social relativamente estável, educados dentro de um projeto de ascensão social.

Tudo se passa como se o contato com a música negra de protesto, assim como a experiência do racismo e da privação, quando associados a uma história de mobilidade social ascendente, tenha impulsionado esses jovens a investir suas energias na abertura e exploração de novos espaços. Isso se concretizou tanto na maior intolerância que desenvolveram com relação às suas condições de vida e às experiências por que foram forçados a passar como pela saída que encontraram: criar grupos de rap e tornar-se protagonistas do movimento hip-hop na cidade.

A mobilidade ascendente relativa que suas famílias experimentaram a partir da geração dos avós foi marcada por um uso intensivo de modestas credenciais escolares que abriram as portas para ocupações não manuais. Ela se concretizou também pelo deslocamento geográfico. Todas as famílias em foco vieram para Campinas na geração dos avós, em busca de melhores condições de vida.

A história de Fabiano, por exemplo, mostra a construção desse projeto. Seus quatro avós vieram para Campinas trabalhar como agricultores numa grande fazenda nas proximidades da cidade. Quando a região onde ficava a fazenda começou a se urbanizar e os proprietários de terras passaram a lotear seus terrenos, seus avós maternos compraram seu próprio lote num novo bairro implantado nessa mesma região e deixaram de ser agricultores para se tornar caseiro, um, e doméstica, outra. A mesma coisa aconteceu com os avós paternos, que também vieram morar nesse novo bairro. Os pais de Fabiano se conheceram ali e, quando se casaram, passaram a morar no quintal da família de sua mãe. Nessa época, o pai trabalhava como ajudante de pedreiro e a mãe, como babá.

Continuando a estudar, mesmo depois de casado, o pai de Fabiano concluiu o curso técnico em Eletrônica. A conclusão do segundo grau, mais do que a competência técnica adquirida, permitiu a ele conseguir um emprego de encanador numa empresa do bairro, passando mais tarde a encarregado de hidráulica, um cargo que incluía também a supervisão do trabalho de uma ou duas pessoas. A mãe, por sua vez, sem avançar muito nos estudos, passou a trabalhar "cuidando" de crianças em transporte escolar. ${ }^{14}$

Com isso, a família pôde se mudar do lote dos avós, onde moravam também outros tios, comprando sua casa própria, embora num bairro mais afastado e mais precário. Isso fez com que a família constituísse, aos poucos, um projeto de futuro para os filhos, ligado fortemente à extensão da escolarização. Tudo

${ }^{14}$ Outros jovens tiveram a mesma trajetória de ascensão social relativa. A mãe de Ivo, por exemplo, filha de um operário não especializado com praticamente nenhuma escolaridade, chegou a cursar o ensino médio e trabalha hoje na área administrativa de uma universidade pública. 
que dissesse respeito à escola era facilitado pelos pais e o discurso corrente em casa vinculava um futuro digno à escola.

Da mesma forma que seus companheiros focalizados aqui, Fabiano concluiu sem retenções o ensino médio numa escola pública de Campinas. São, assim, bons alunos em escolas mal aparelhadas que têm grandes dificuldades para garantir a esses jovens as competências necessárias para ter sucesso nas carreiras escolares mais prestigiadas. Isso os impede de resolver pela escola um plano de futuro no qual investiram todas as suas fichas.

Assim, não é por acaso que a criação dos grupos de rap acontece no início do ensino médio. Tudo se passa como se, nesse momento, esses jovens começassem a sentir ou a pressentir que os investimentos escolares não seriam suficientes para levá-los mais adiante.

Poupado pela família do trabalho remunerado em prol da escolarização, com a finalização do ensino médio Fabiano viu-se obrigado a procurar alguma remuneração. Conseguiu alguns trabalhos temporários, "bicos". Foi ajudante geral numa escola de tênis, office-boy, garçom em bar, ajudante de encanador. Ocupações que lhe pareciam absolutamente desestimulantes, insuficientes.

Situação parecida é enfrentada por seus amigos e o sonho de se tornar Mano Brown os leva a investir mais pesado no rap. Eles criam, assim, os seus primeiros grupos e passam a lutar, sem muito sucesso, para se inserir na cena hip-hop de Campinas.

No entanto, os investimentos familiares não foram apenas de ordem escolar, ou de adesão à lógica presente na escola. Houve também um investimento forte na educação moral de Fabiano, transmitida tanto na forma de ensinamentos e preceitos, quanto na insistência para que obtivesse formação religiosa católica, no caso.

O meu pai me passou valores muito bons. Meu pai é uma pessoa super simples e, em alguns aspectos, uma pessoa conservadora. [...] Mas ele sempre me passou uma coisa assim de honestidade, de responsabilidade. Meu pai, mesmo que a gente sempre morou em periferia, nunca frequentou bar, nunca teve problema com álcool, como muitas famílias às vezes tinham com o chefe da casa, que era o homem da casa, que trabalhava e no dia do pagamento gastava todo o dinheiro e chegava com uma mão na frente e outra atrás. Ou mesmo com drogas e essas coisas. O meu pai, nesse aspecto, sempre lutou muito para ter uma vida digna. Então, essa é uma coisa que eu guardo muito do meu pai. Agora, a minha mãe [...], que só estudou até a quarta série, apesar disso é a pessoa que mais lê, sempre lê e é uma pessoa que tem visão. [...] Porque sempre me passou coisas super positivas, principalmente a questão dos estudos. Nunca me cobraram. Apesar de a gente ter passado por períodos difíceis do ponto de vista financeiro, a prioridade sempre foi estudar. Nunca me cobraram obrigatoriamente que eu tivesse que trabalhar, sempre priorizaram a questão dos estudos. Se desse para eu trabalhar tudo bem, mas se eu não quisesse trabalhar também nunca me obrigaram, e eu acho isso importante para mim, porque possibilitou que eu tivesse estudado e eu acho isso daí positivo. (Entrevista de pesquisa, Campinas, 2006)

Esse investimento escolar e moral, que parece ser ponto de constituição da figura do trabalhador dedicado, disciplinado em rota social ascendente, teve efeitos sobre vários momentos da trajetória desse jovem, sobre seus encontros e sobre as alianças posteriores no campo da militância que ele pôde fazer. Com os outros, as coisas se passaram mais ou menos da mesma maneira. Ivo, por exemplo, conta como o avô e a mãe são trabalhadores dedicados e disciplinados. Usa como evidência disso o fato de que sua mãe vai se aposentar sem nunca ter faltado ao trabalho, como aconteceu também com seu avô. Outros dois jovens, Joãozinho e Túlio, apesar de apresentarem condição econômica mais precária que a de Ivo e a de Fabiano, dizem que suas mães sempre os estimularam a procurar viver com dignidade, isto é, honrado, sem se envolver com roubos. Nessa sintonia, eles exerceram, ainda na infância, atividades esporádicas como engraxate ou vendedor ambulante para auxiliar na renda familiar. Para as mães, essa era também uma maneira de fazer os filhos não se misturaram com o universo da criminalidade presente nos seus bairros. 
O contato com o rap e, principalmente, com a cena rap representa, então, o momento em que as disposições construídas ao longo dos processos de socialização, tanto nos espaços controlados pela família quanto naqueles controlados pela escola, organizadas em torno da valorização da dedicação ao trabalho, do esforço e da disciplina, podem ser colocadas a serviço da construção de um projeto de ascensão social ligado ao show business.

\section{A entrada em militância}

No entanto, confrontando com uma cena hip-hop dominada pelos trabalhos dos rappers norte-americanos e paulistanos, os jovens campineiros não encontram espaço para se apresentar e divulgar seu trabalho.

Por volta de 1994, esses jovens estavam finalizando o ensino fundamental, fortemente motivados por suas famílias, como vimos, a prosseguir os estudos, iniciando o ensino médio. Como os bairros de periferia onde moravam tinham poucas escolas que oferecessem esse nível de ensino, e eles buscavam além disso escolas mais bem conceituadas, a entrada no antigo $2^{\circ}$ grau significou mudar de escola e passar a frequentar aulas no período noturno em outros bairros mais próximos do centro da cidade ou no próprio centro. Ali, esses jovens apreciadores de rap descobriram rapidamente os bailes que aconteciam no centro da cidade, em casas noturnas que geralmente ficavam muito próximas do terminal de ônibus que usavam para voltar para casa depois das aulas, o que facilitava o deslocamento e o encontro com outros jovens de diferentes regiões que compartilhavam gostos musicais e características sociais muito próximas. Não demorou para que a circulação por um circuito de bailes e bares acabasse por permitir a formação de uma rede de amizade entre eles. ${ }^{15}$

${ }^{15}$ As ideias de pedaço, manhas, trajetos e circuitos desenvolvidos por Magnani (1996) contribuem para compreender de que maneira a ocupação do espaço urbano pode permitir a aproximação de grupos de diferentes lugares a partir de gostos e estilos em comum.
Essa rede aglutinava desde jovens interessados em tornar-se eles próprios artistas do hip-hop, alguns dos quais já haviam até mesmo formado seus próprios grupos de rap, até aqueles que se definiam apenas como apreciadores ou mesmo fãs de alguns desses grupos que vinham de ser criados.

É nesses encontros e conversas aparentemente casuais que acontecem ao ar livre, nos bancos das praças do centro da cidade mas também em salões de bailes, que esses jovens compartilham a frustração de não ter muitas chances de divulgar seus trabalhos, apoiam-se mutuamente, valorizando o trabalho uns dos outros e sonhando com a possibilidade de entrar no mercado rap, de chegar ao estrelato. A aglutinação deriva fundamentalmente da queixa em relação aos empresários das casas noturnas que tocavam rap na cidade, pois, segundo eles, os empresários lucravam com os bailes mas pagavam mal aos rappers; não davam oportunidades aos grupos de rap da cidade de se apresentarem, além de frequentemente cancelarem shows sem devolver o dinheiro ao público.

Procurando se inserir no mercado do rap de Campinas, os jovens rapidamente perceberam que seria muito difícil conseguir um espaço nesse universo de poucas oportunidades e de alta competitividade. A articulação com outros grupos tão ambiciosos quanto eles se deu como uma estratégia considerada "natural” por eles, para confrontar o que percebiam como “poderes estabelecidos”, isto é, os empresários e produtores que investiam no rap. Reagindo, assim, muito rapidamente, ao que percebem como "exploração” dos empresários do circuito, eles constroem a ideia de que são um "grupo", o grupo dos rappers campineiros, e decidem se organizar coletivamente para lutar por seus interesses.

Tinha as panelinhas do grupo X, do grupo Y, tinha baileiros, como em todo lugar. Só que assim, isso, como em todo lugar, prejudica. E aqui em Campinas a gente quis fazer diferente disso tudo, então o pessoal que estava excluído das panelinhas e dos eventos dos baileiros se organizou um dia e falou: “Ah, vamos fazer um evento só nós”. Começou assim como uma brincadeira. “Ah, não, pára... não sei o quê... isso dá trabalho”. 
“Ah, vamos fazer isso sim, meter a cara”. “Ah, vamos!” Aí eu lembro até hoje que isso foi dentro de um salão, estava rolando um rap, tal. A gente tudo curtindo, tomando cerveja.

“Pô, vamos fazer!” "Vamos.” E ali tudo foi uma sementinha que plantou na cabeça de cada um. Depois a gente começou a se juntar, fazer reunião em praça, igual a gente tá fazendo agora. (Entrevista de pesquisa com Ivo, Campinas, 2005)

Esses garotos e garotas investem suas energias e capacidades, fruto de uma forma particular de socialização, na organização coletiva de vários grupos de rap em torno do projeto de criação de uma associação que lute pelos seus interesses. Pensam, nesse momento, que uma associação lhes permitirá dar maior visibilidade ao hiphop produzido em Campinas, contribuindo para fazer os produtores culturais da cidade sentirem um interesse em contratá-los ou thes dar mais espaço. A associação poderá também, na sua visão, otimizar seus esforços para conseguir a participação dos grupos associados em eventos promovidos na cidade. Além disso, pretendem fazer da associação um espaço de reflexão sobre as denúncias que fazem em suas músicas e um mediador da articulação dos rappers. Por fim, pretendem desenvolver uma série de ações sociais voltadas para as periferias.

Criada em 1998, a partir de uma aproximação dos jovens com sindicatos e partidos organizados, a Associação Posse Rima \& Cia. encaminhou com bravura e competência essas lutas, abrindo um espaço inédito para a veiculação de grupos campineiros que se encontravam na obscuridade e articulando suas demandas às lutas encaminhadas por outros movimentos sociais na cidade. Muito rapidamente, já em 2000, eles se engajaram na campanha de um dos candidatos à prefeitura da cidade. A vitória desse candidato lhes permitiu reivindicar - e obter - a criação, pela Secretaria de Cultura, da Casa do Hip-Hop de Campinas.

\section{Considerações finais}

Neste texto, procuramos demonstrar a produtividade analítica de pensar a militância juvenil como resultado do encontro entre uma série de disposições construídas ao longo dos processos de socialização e de uma situação histórica bem determinada, caracterizada, no caso, pela presença de: a) uma forma artística de protesto e denúncia social produzida por jovens de origem popular no cenário cultural nacional; b) uma escola pública que não consegue prover os jovens de origem popular dos recursos necessários para uma inserção ocupacional de classe média para a qual foram empurrados por suas famílias, inserção cada vez mais regulada por diplomas e competências escolares; c) uma organização particular do subespaço artístico onde se desenvolve o hip-hop na cidade de Campinas, isto é, sua subordinação aos grupos aclamados nas cenas hip-hop dominantes, localizadas na cidade de São Paulo e nos Estados Unidos. Frente a uma situação assim esquematizada, o grupo de jovens focalizado neste trabalho volta-se para uma ação militante, estendendo sua ação para além da composição de músicas de protesto até entrar no território das ações coletivas.

Acreditamos que entender os processos que lhes permitiram dirigir as energias para esse empreendimento, articulando as operações de socialização às experiências que tiveram em uma determinada configuração do espaço social por onde se moveram, é condição crucial para compreender como essa história foi possível. Isso implicou tratar esta situação não como um "caso particular”, mas como um "caso particular entre os casos possíveis”, na formulação usada por Pierre Bourdieu (1992) ou, na visão de Norbert Elias (2000), como um “microcosmo”, a partir do qual foi possível problematizar situações-chave que definem a entrada em militância.

Os resultados obtidos contribuem, assim, para reforçar a hipótese de que a ação política não é algo natural nem imediato, que não está inscrita igualmente em todos os indivíduos, mas resulta da interação estreita de vários processos. Essas conclusões podem contribuir para refinar nossa percepção sobre a participação política dos jovens e ajudar a perceber que a visão espontaneísta da militância política embutida em certas críticas à "falta de participação dos jovens" perde de vista o papel fundamental do trabalho, muitas vezes inconsciente, envolvido numa socialização que predisponha a tal participação, seja ele desenvolvido 
pela família ou por sindicatos e grupos políticos de todo tipo. Atribuindo aos indivíduos a "falta de interesse” na participação, esses críticos deixam de indagar sobre os interesses mobilizados por tais grupos quando se envolvem ativamente na constituição de disposições que levam à militância juvenil ou quando consideram que essa questão não lhes concerne.

\section{Referências bibliográficas}

ABRAMO, Helena Wendel. Cenas juvenis: punks e darks no espetáculo urbano. São Paulo: Scritta, 1994a.

. Considerações sobre a tematização social da juventude no Brasil. Revista Brasileira de Educação, n. 5/6, p. 25-36, 1994b.

BOURDIEU, Pierre. O desencantamento do mundo: estruturas econômicas e estruturas temporais. São Paulo: Perspectiva, 1979. BOURDIEU, Pierre. A “juventude” é apenas uma palavra. In: BOURDIEU, Pierre. Questões de sociologia. Rio de Janeiro: Marco Zero, 1983. p. 112-121.

. Invitation to a reflexive sociology. Chicago: Chicago University Press, 1992.

. Gosto de classe e estilo de vida. In: ORTIZ, Renato.

Pierre Bourdieu. São Paulo: Ática, 1994. p. 82-121. (Coleção

Grandes Cientistas Sociais.)

. Espaço social e gênese das classes. In: BOURDIEU,

Pierre. O poder simbólico. 3. ed. Rio de Janeiro: Bertrand Brasil, 2000. p. 133-161.

EDELMAN, Marc. Popular culture as pppositional culture: rap as resistance. Annual Review of Anthropology, v. 30, p. 285-317, 2001.

ELIAS, Norbert. Introdução à sociologia. Lisboa: Edições 70, 1980. Os estabelecidos e os outsiders: sociologia das relações de poder a partir de uma pequena comunidade. Rio de Janeiro: Jorge Zahar, 2000.

FILLIEULE, Oliver. Proposition pour une analyse processuelle de l'engagement individuel. Revue Française de Science Politique, v. 51, n. 1-2, p. 199-217, fév./avr., 2001.

LIMA, Mariana Semião de. Rap de batom: família, educação e gênero no universo rap. Dissertação (Mestrado em Educação) - Faculdade de Educação, Universidade Estadual de Campinas, Campinas, 2005.

MAGNANI, José Guilherme Cantor. Quando o campo é a cidade: fazendo antropologia na metrópole. In: MAGNANI, José Guilher- me; TORRES, Lilia de Lucca (Orgs.). Na metrópole - textos de antropologia urbana. São Paulo: EDUSP/FAPESP, 1996. p. 15-53. MARTINEZ, Theresa A. Social movements: changing paradigms and forms of politics. Sociological Perspectives, v. 40, n. 2, p. 265-286, 1997.

MORENO, Rosangela Carrilo. As mutações da experiência militante: um estudo a partir do movimento hip-hop de Campinas. Dissertação (Mestrado em Educação) - Faculdade de Educação, Universidade Estadual de Campinas, Campinas, 2007.

OFFERLÉ, Michel. Sociologie des groupes d'interêt. Paris: Montchrestien, 1994.

OLSON, Mancur Jr. A lógica da ação coletiva: benefícios públicos e uma teoria dos grupos sociais. São Paulo: EDUSP, 1999. (1. ed. The logic of collective action: public goods and the theory of groups. Cambridge: Harvard University Press, 1965.)

OSTROM, Elinor. Collective action and the evolution of social norms. The Journal of Economic Perspectives, v. 14, n. 3, p. 137158, summer 2000.

ROSE, Tricia. Black noise: rap music and black culture in contemporary America. Middletown: Wesleyan University Press, 1994. SILVA, José C. G. Rap na cidade de São Paulo: música, etnicidade e experiência urbana. Tese (Doutorado em Ciências Sociais) Instituto de Filosofia e Ciências Sociais, Universidade Estadual de Campinas, Campinas, 1998.

SIMÉANT, Johanna. Entrer, rester em humanitaire: des fondateurs du MSF aux membres actuels des ONG Médicales Française. Revue Française de Science Politique, v. 51, n. 1-2, p. 47-72, fév./avr. 2001.

SMITH, Sophy. Compositional strategies of the hip-hop turntablist. Organised Sound, v. 5, n. 2, p. 75-79, 2000.

WELLER, Wivian. Práticas culturais e orientações coletivas de grupos juvenis: um estudo comparativo entre jovens negros em São Paulo e jovens de origem turca em Berlim. In: ENCONTRO DAASSOCIAÇÃO BRASILEIRA DE ESTUDOS POPULACIONAIS, 13., 2002. Anais... Ouro Preto: s.ed., 2002.

ROSANGELA CARRILO MORENO, doutoranda no Grupo de Estudos sobre Instituição Escolar e Organizações Familiares (grupo FOCUS) da Faculdade de Educação da Universidade Estadual de Campinas (UNICAMP), é pesquisadora do projeto temático “Circulação Internacional e Formação dos Quadros Dirigentes Brasileiros”, coordenado pela professora Letícia Bicalho Canêdo. Publicações recentes: com ALMEIDA, Ana Maria F., 
“Isso é política, meu! Socialização militante e institucionalização dos movimentos sociais" (Pro-posições, no prelo) e "Juventude e política: o processo de desengajamento" (Cadernos CERU, no prelo).E-mail:rocarrilo@yahoo.com.br

ANA MARIA F. ALMEIDA, doutora em educação pela Universidade Estadual de Campinas (UNICAMP), é professora da Faculdade de Educação e cocoordenadora do Grupo de Estudos sobre Instituição Escolar e Organizações Familiares (Focus), nessa mesma universidade. Publicações recentes: A noção de capital cultural é útil para pensar o Brasil? (na coletânea organizada por Nadir Zago e Lea Paixão, Sociologia da educação: pesquisa e realidade brasileira. Petrópolis: Vozes, 2007. p. 44-59); organizou com Maria Alice
Nogueira, Escolarização das elites: um panorama internacional da pesquisa (Petrópolis: Vozes, 2002); com Letícia Canêdo, Afrânio Garcia e Agueda Bittencourt, Circulação internacional e formação das elites brasileiras (Campinas: Editora da UNICAMP, 2004); organizou também os dossiês: "Sociologia da educação” (Revista Tempo Social, v. 20, n. 1, jun. 2008) e "Experiências educativas e construção de fronteiras sociais” (Educação \& Sociedade, v. 29, n. 103, maio/ago. 2008). Desenvolve atualmente pesquisa que procura compreender como os economistas se transformaram em produtores de políticas públicas de educação.E-mail: aalmeida@unicamp.br

Recebido em julho de 2008 Aprovado em setembro de 2008 